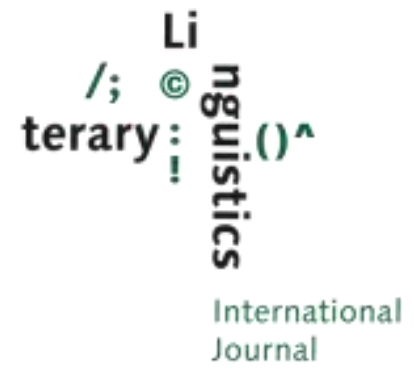

\title{
Introduction: Literary Texts and their Translations as an Object of Research
}

\author{
Keywords: \\ Literary \\ translation, \\ retranslation, \\ indirect \\ translation, \\ translation \\ universals, \\ hybridity, \\ heterolingual- \\ ism, language \\ contact
}

\section{Leena Kolehmainen, Esa Penttilä and Piet Van Poucke, University of Eastern Finland and Ghent University}

This special issue of the International Journal of Literary Linguistics offers seven state-of-the-art contributions on the current linguistic study of literary translation. Although the articles are based on similar data - literary source texts and their translations - they focus on diverse aspects of literary translation, study a range of linguistic phenomena and utilize different methodologies. In other words, it is an important goal of this special issue to illuminate the current diversity of possible approaches in the linguistic study of translated literary texts within the discipline of translation studies. At the same time, new theoretical and empirical insights are opened to the study of the linguistic phenomena chosen by the authors of the articles and their representation or use in literary texts and translations. The analyzed features range from neologisms to the category of passive and from spoken language features to the representation of speech and multilingualism in writing. Therefore, the articles in this issue are not only relevant for the study of literary translation or translation theory in general, but also for the disciplines of linguistics and literary studies - or most importantly, for the cross-disciplinary co-operation between these three fields of study.

The common theme that all these articles share is how the translation process shapes, transfers and changes the linguistic properties of literary texts as compared to their sources texts, other translations or non-translated literary texts in the same language and how this question can be approached in research. All articles provide new information about the forces that direct and affect translators' textual choices and the previously formulated hypotheses about the functioning of such forces. The articles illustrate how translators may perform differently from authors and how translators' and authors' norms may diverge at different times and in different cultures. The question of how translation affects the linguistic properties of literary translations is approached from the viewpoint of previously proposed claims or hypotheses about translation. In the following, we will introduce these viewpoints for readers who are not familiar with the recent developments in translation studies. At the same time, we will shortly present the articles in this issue. 


\section{New insights into the retranslation hypothesis and indirect translation}

This special issue is opened by two articles that relate to one of the research themes that was clearly under-investigated until the 1990s but has attracted a lot of attention in Translation Studies recently (see e.g. Deane-Cox 2014; Alvstad \& Assis Rosa 2015). This theme is retranslation in its double sense of "the act of translating a work that has previously been translated into the same language" and "the result of such an act, i.e. the retranslated text itself" (Gürçağlar 2009: 233). Ever since Berman (1990) started up the discussion in his introductory article of the seminal issue of Palimpsestes, analysis of the phenomenon has mainly focused on the reasons and motives for retranslation. Two main lines of investigation have up till now received the lion's share of attention: first, the (alleged) ageing character of an earlier translation, a phenomenon that is nearly taken for granted in non-professional reviews of literary translations, but for which not much empirical evidence has been provided so far, and secondly, the retranslation hypothesis, the assumption put forward by Berman (1990) that later translations tend to be closer to the source text than the first translation of a literary work.

The retranslation hypothesis is one of the issues of retranslation theory (Brownlie 2006), raised in the paper by Marlies Prinzl, in connection with a number of other universals of translation - normalization of literary works in translation. One of the innovative features of her paper is that she does not only compare a first and subsequent translation mutually, as is often the case in retranslation research, but includes eleven different English translations of Der Tod in Venedig by Thomas Mann in the analysis, thus creating a diachronic cross-section of translators' solutions to Mann's linguistic creativity. Prinzl investigates how (re)translators handle the neologisms of the original and how they try to retain the stylistic characteristics of the source text. The degree of originality of the neologisms in both source and target text is determined by using corpus-linguistic methods. The study reveals that none of the translators between 1924 and 2012 manage to retain the level of creativity present in the source text, and, on the contrary, resort to normalizing (standardizing) translation strategies, at the same time undermining the retranslation hypothesis.

Technically speaking, an indirect translation of a literary work, i.e. the translation of a source text via a first translation into a third language, also resorts under the general umbrella of retranslation. The characteristics of indirect translation, however, differ significantly from retranslation proper, as the objectives of both types of translation are almost diametrically opposed. Whereas a retranslator generally aims at creating added value (Venuti 2013) by improving on an earlier translation (by making a more accurate or stylistically and culturally more appropriate version of the text), an indirect translator is not directed toward the source text (which is usually unknown to the translator) and runs the risk of weakening the fidelity of the translation even more than was the case in the first translation, due to the lacking access to the source text. Nevertheless, indirect translation, also called "mediated" or "second-hand" translation (Toury 1995: 
129-146), is an old and widespread practice (cf. the majority of Bible translations were made via intermediate versions of the source text) that is still understudied and lacks an academic terminology to describe many of the processes at work.

In her paper on David Bellos' indirect translation of Ismail Kadare's novel The File on $H$ from Albanian, through the "mediating language" French, into English, Silvia Kadiu investigates whether recurring linguistic shifts can be discerned that are the immediate result of the process of indirect translation. Hypothetically, the resulting English target text should suffer not only from the defects of the first act of translation (which are expected to be repeated in the second translation), but also from a number of newly created deviations from the source text, made during the second act of translation. Kadiu shows, however, that no clear patterns of this kind can be empirically proven in indirect translation and that we are rather dealing with a "continuum" of "indirectness" than a binary opposition between the source text on the one hand, and the so-called deficient indirect translation on the other.

\section{The representation of speech and the universals of translation}

The next two articles continue another research tradition in translation studies that also became vivid in the 1990s. This is the study of the so-called translation universals that refers to the hypotheses - originally suggested by Blum-Kulka (1986) and Baker (1993) and empirically tested, for example, in the articles of the collective volume by Mauranen and Kujamäki (2004) - that the linguistic properties of translated texts tend to differ in a systematic way either from their source texts or from comparative non-translated texts in the same language and that these differences occur irrespective of the language pair, culture, time or text type. Most of the research on translation universals has been corpuslinguistic, and the proposed hypotheses have been both empirically supported and criticized. One intensively investigated universal hypothesis is the normalization (standardization) hypothesis according to which translated texts are typically linguistically more "scrutinized" than non-translated texts (including the source texts) so that they, for example, entail less linguistic variation and more standard language features or rely on more conventional means of expression instead of unconventional ones. In this special issue this hypothesis is discussed in two articles that both challenge it, but in different ways. The articles study the representation of speech and spoken language features in literary translations.

In Liisa Tiittula's and Pirkko Nuolijärvi's article, whose data consists of Finnish translated literature from the 1900s to the early 2000s, the translation of spoken language features in dialogue and narration is investigated. The comparison of Finnish translations to their source texts and to comparative non-translated Finnish literature from the same era shows that, although there is a strong tendency towards the suppression of colloquial features in literary translations, i.e. normalization, the norms guiding the translation of spoken language features 
have varied at different times and in different genres so that the universal nature of normalization is questioned.

Päivi Kuusi's article, in turn, discusses free indirect discourse in Fedor Dostoyevsky's Crime and Punishment and its manifestation in the first Finnish translation and the subsequent retranslations dating from 1888-2008. Her linguistic analysis reveals several shifts from free indirect discourse to direct and indirect discourse that can be interpreted as instances of normalization in the translations. The interdisciplinary comparison of the translation studies' notion of normalization with the narratological and literary-theoretical notions of reportive interference and typification shows that these terms largely coincide. In other words, the tendencies predicted by the hypotheses of translation universals are not exclusive for translations but also occur in other forms of mediated discourse. By suggesting that translation universals could be regarded as translation-specific manifestations of the larger phenomenon of mediation universals Kuusi's article calls for a deeper interdisciplinary co-operation between narratology, literary theory and translation studies.

\section{Translating multilingual texts}

The representation and translation of speech and spoken language features is also one of the topics of the next two articles, which widen the perspective towards multilingualism. Multilingualism in writing is an old phenomenon (see e.g. Skaffari 2016), but interestingly it is a topic that has not been investigated as intensively as multilingualism in spoken interaction. For example, the articles in the collective volume edited by Sebba, Mahootian and Jonsson (2012) highlight that the ways in which code-switching and code-mixing (and other related phenomena) are utilized in writing may differ from spoken language, and that in this respect, the exploration of written texts may open new insights into their functions. Another effect of current multilingualism are the so-called multiethnolects, multilingual varieties in multiethnic urban surroundings in which the youth creatively combine elements and features of their linguistic repertoire. Also their investigation has been vivid in the study of spoken multilingualism (see e.g. Quist 2008; Lehtonen 2015; Wiese 2012).

The representation of this kind of hybridity or heterolingualism in literary texts constitutes a topic that has recently started to interest literary and translation scholars. The heterolingualism of a literary text poses specific translation problems as it goes beyond the usual transfer process from one source into one target language. Hybrid language being very culture-specific on the one hand, and somewhere 'in between' cultures on the other, it usually lacks a clear equivalent in another language, which narrows down the number of possibilities for the translator. Hence, when translating non-standard language, whether that be multiethnolect, slang, dialect, regiolect or sociolect, literary translators are faced with the 'illusion of authenticity' that they try to attain by transferring not only the message, but also the style of a literary work. This transfer is especially difficult to realize when the stylistic features of a text are embedded in one particular culture and/or period, and are not transferable in themselves. For 
instance, translating Paris argot into London cockney only makes sense if the setting of the literary work is not Paris.

Stella Linn addresses such issues of multilingualism and sociolect in her paper on the translation of urban multiethnic youth slang from French into Dutch. Based on a detailed analysis of youth slang in French and Dutch, she tries to find similarities between the two and investigates to what extent possible parallelisms may be used by literary translators to give the reader of the target text a flavor of the original one, without harming the coherence of the narrative and the credibility of the translation. Her contrastive survey of linguistic features in both varieties of youth slang aims to assess the different options available to translators, thus streamlining translation of this particular literary genre in one particular translational direction (French-Dutch).

Simo Määttä's data, in turn, consist of four Swedish coming-of-age stories in which the protagonists, migrants and/or minority language speakers, grow up in a hybrid space between two or more languages and cultures. The focus of this article is on the representation of sociolinguistic variation and on the question of how authors reflect - or refract - minority language speakers' voices, regional dialects, migrants' L2 varieties and other languages - and the linguistic and social hybridity of the protagonists' and other characters' multicultural lives. The linguistic analysis of the source texts, which is carried out on the speech and thought representation, is followed by an analysis of the Finnish translations. These are shown to entail shifts that affect the speech and thought representation and the relations between the characters in the story and the image of the narrator.

\section{Approaching the contact-linguistic study of translation}

The novels that form the research material of the articles by Stella Linn and Simo Määttä relate to aspects of individual and societal multilingualism, and they partly describe linguistic encounters between speakers with varying linguistic repertoires and the effects of such encounters. Language contact and its effects are the central topics of research in contact linguistics, in which, however, translation as a mode of language contact has not yet been intensively investigated (see also Kranich, Becher \& Höder 2011; McLaughlin 2011; Witalisz 2015). In translation studies, in turn, a new research area which combines perspectives of translation studies and contact linguistics has recently started to emerge. The nature of translation as language contact, the ways in which it operates and how it possibly shares properties with other language contact situations are central questions posed within this new field of study.

In the final article by Leena Kolehmainen and Helka Riionheimo literary translation is viewed as a mode of language contact and approached from the viewpoint of the contact-linguistic study of translation. The central questions in this article are methodological: Does literary translation leave similar traces as other language contacts which take place between ordinary language speakers and not language professionals, and with which methods can this phenomenon 
be investigated? A corpus-linguistic pilot analysis in which Finnish literary translations from Estonian and German are compared to Finnish non-translated literary texts is carried out on the Finnish passive, a category that closely resembles the Estonian passive but strongly diverges from the German passive. The pilot reveals some features that differentiate the literary translations from non-translated literary texts, but more importantly, it points out ways how the tested methodology should be adjusted and further developed.

In sum, the articles in this special issue provide a variety of fresh approaches to previously formulated claims and hypotheses about the nature of the translation process and the linguistic properties of translated texts, and they illuminate current developments in their study. We guest editors hope that the articles will stimulate fruitful discussions, plenty of new empirical research and crossdisciplinary co-operation between scholars working in linguistics, translation studies and literary studies.

Current issues in the linguistic analysis of literary translations is a collection of articles that has been reviewed anonymously by a number of external experts. The published articles have been selected on the basis of the reviewers' reports. We would like to express our deepest gratitude to all reviewers for their critical comments and questions, constructive feedback and valuable suggestions that helped the authors to improve their texts before publication.

Ghent and Joensuu March 23, 2016

Leena Kolehmainen, Esa Penttilä and Piet Van Poucke

\section{References}

Alvstad, Cecilia \& Assis Rosa, Alexandra (eds.) (2015). Voice in Retranslation. Special issue of Target: International Journal of Translation Studies, 27(1).

Baker, Mona (1993). Corpus Linguistics and Translation Studies. Implications and Applications. Text and Technology. In honour of John Sinclair, eds. Mona Baker, Gill Francis \& Elena Tognini Bonelli. Amsterdam and Philadelphia: John Benjamins, 233-250.

Berman, Antoine (1990). La retraduction comme espace de la traduction, Palimpsestes $4,1-7$.

Blum-Kulka, Shoshana (1986). Shifts of Cohesion and Coherence in Translation. Interlingual and Intercultural Communication. Discourse and Cognition in Translation and Second Language Acquisition, eds. Juliane House \& Shoshana Blum-Kulka. Tübingen: Narr, 17-35.

Brownlie, Siobhan (2006). Narrative Theory and Retranslation Theory, Across Languages and Cultures 7(2), 145-170. 
Deane-Cox, Sharon (2014). Retranslation. Translation, Literature and Reinterpretation. London: Bloomsbury.

Lehtonen, Heini (2015). Tyylitellen. Nuorten kielelliset resurssit ja kielen sosiaalinen indeksisyys monietnisessä Helsingissä. University of Helsinki, Department of Humanities. Available at: https://helda.helsinki.fi/bitstream/handle/10138/155659/tyylitel.pdf?sequence=1

Kranich, Svenja, Becher, Viktor \& Höder, Steffen (2011). A Tentative Typology of Translation-Induced Language Change. Multilingual Discourse Production. Diachronic and Synchronic perspectives, eds. Svenja Kranich, Viktor Becher, Steffen Höder \& Juliane House. Amsterdam and Philadelphia: John Benjamins, 1143.

Mauranen, Anna \& Kujamäki, Pekka (eds.) (2004). Translation Universals. Do They Exist? Amsterdam and Philadelphia: John Benjamins.

McLaughlin, Mairi (2011). Tradurre/Tradire: Translation as a Cause of Linguistic Change from Manuscripts to the Digital Age. UC Berkeley, The University Library New Faculty Lecture Series. Berkeley: The Doe Library.

Quist, Pia (2008). Sociolinguistic Approaches to Multiethnolect. Language Variety and Stylistic Practice, International Journal of Bilingualism, 12(1\&2), 43-61.

Sebba, Mark, Mahootian, Shahrzad \& Jonsson, Carla (eds.) (2012). Language Mixing and Code-Switching in Writing. Approaches to Mixed-Language Written Discourse. New York and London: Routledge.

Skaffari, Janne (2016). Code-Switching and Vernacular Support. An early Middle English Case Study, Multilingua 35(2), 203-226.

Gürçağlar, Şehnaz Tahir (2009). Retranslation. The Routledge Encyclopedia for Translation Studies, eds. Mona Baker \& Gabriela Saldanha. London and New York: Routledge, 233-236.

Toury, Gideon (1995). Descriptive Translation Studies. Amsterdam and Philadelphia: John Benjamins.

Venuti, Lawrence (2013). Retranslations. The Creation of Value. Translation Changes Everything. Theory and Practice. London and New York: Routledge.

Wiese, Heike (2012). Kiezdeutsch. Ein neuer Dialekt entsteht. München: C. H. Beck Verlag.

Witalisz, Alicja (2015). English Loan Translations in Polish. Word-Formation Patterns, Lexicalization, Idiomaticity and Institutionlization. Pieterlenn: Peter Lange. 